\title{
Competition between a sugar beet crop and populations of Chenopodium album L. and Stellaria media L.
}

M. J. Kropff ${ }^{1}$, W. Joenje ${ }^{2}$, L. Bastiaans ${ }^{1,2}$, B. Habekotté ${ }^{1,2}$, H. van Oene va $^{1.2}$ and R. Werner ${ }^{1.2}$ ( ${ }^{1}$ Department of Theoretical Production Ecology, Agricultural University, P.O. Box 430, 6700 AK Wageningen, Netherlands; ${ }^{2}$ Department of Vegetation Science, Plant Ecology and Weed Science, Agricultural University, Wageningen, Netherlands)

Received 9 April 1987; accepted 29 July 1987

\begin{abstract}
Competition between a sugar beet crop and populations of Chenopodium album L. (fat hen) and Stellaria media L. (chickweed) was studied in field experiments. Fat hen plants reduced crop production by $37 \%$ at a density of 5.5 plants per $\mathrm{m}^{2}$, while chickweed reduced crop production by $21 \%$ at a density of 11 clumps per $\mathrm{m}^{2}$. Although chickweed populations had a much higher leaf area index, fat hen appeared to be the stronger competitor to sugarbeets because fat hen plants grew much taller and were able to overgrow the sugar beets.
\end{abstract}

Key words: competition, sugar beet, weed, Chenopodium album, Stellaria media

Introduction. Weeds can reduce crop growth by competition for light, water and nutrients, especially in crops such as sugar beets which need a long growing period to form a closed canopy. Quantitative information about expected yield losses at different weed infestations is required for the development of weed control advisory systems.

The effect of weeds on crop yield may vary strongly among years (Kropff et al., 1984). Theoretical studies on crop-weed competition with dynamic simulation models (Spitters, 1984; Kropff, 1987) have suggested that both relative time of emergence and morphological characteristics, such as plant height and leaf area, may strongly influence competitive ability. To analyse the influence of weed morphology on competitive ability, a field experiment was designed with sugar beets in mixture with fat hen (Chenopodium album L.) and sugar beets in mixture with chickweed (Stellaria media L.).

Materials and methods. In 1985, the growth of sugar beets (Beta vulgaris L. cv. Monohil), fat hen (Chenopodium album L.) and chickweed (Stellaria media L.) was analysed by frequent harvesting of monocultures and a mixture of the sugar beets with each of the weed species. The field experiment (a split-plot design with 4 replicates) was performed in Wageningen on a sandy loam soil (4\% organic matter) with an adequate supply of nutrients and water. Sugar beet plants were grown at a spacing of $30 \times 30 \mathrm{~cm}^{2}\left(11\right.$ plants per $\left.\mathrm{m}^{2}\right)$. The weeds were equally distributed be- 
tween the sugar beet plants. Fat hen was sown at 5.5 plants per $\mathrm{m}^{2}$ in mixture with sugar beets and at 11 plants per $\mathrm{m}^{2}$ in monoculture. Chickweed was grown at 11 clumps of plants (consisting of 10-20 plants per clump) per $\mathrm{m}^{2}$ in mixture with sugar beets and in monoculture. The net plot size was $6 \times 1.5 \mathrm{~m}^{2}$. Average dates of emergence for sugar beet, fat hen and chickweed were 9 May, 21 May and 20 May, respectively.

Results and discussion. The time course of sugar beet growth in monoculture and in mixtures with fat hen and chickweed is presented in Fig. 1. Crop biomass reduction by weed competition first appeared in July and increased in August and September. The effect of fat hen on sugar beet production was much stronger than the effect of chickweed. Table 1 shows the effect of the weed species on several production characteristics of the sugar beets at final harvest. Total dry matter of the sugar beets was reduced $37 \%$ by fat hen and $21 \%$ by chickweed at final harvest. The same pattern was found in the sugar yields of the crop (Table 1). Analysis of data on rainfall, soil water content and calculated evapotranspiration showed that water stress did not occur in the experiment. An analysis with a simulation model of crop growth under nitrogen shortage indicated that nitrogen did not limit crop growth in mixture or in monoculture. From these results it was concluded that competition for light was the main factor causing differences in sugar beet production.

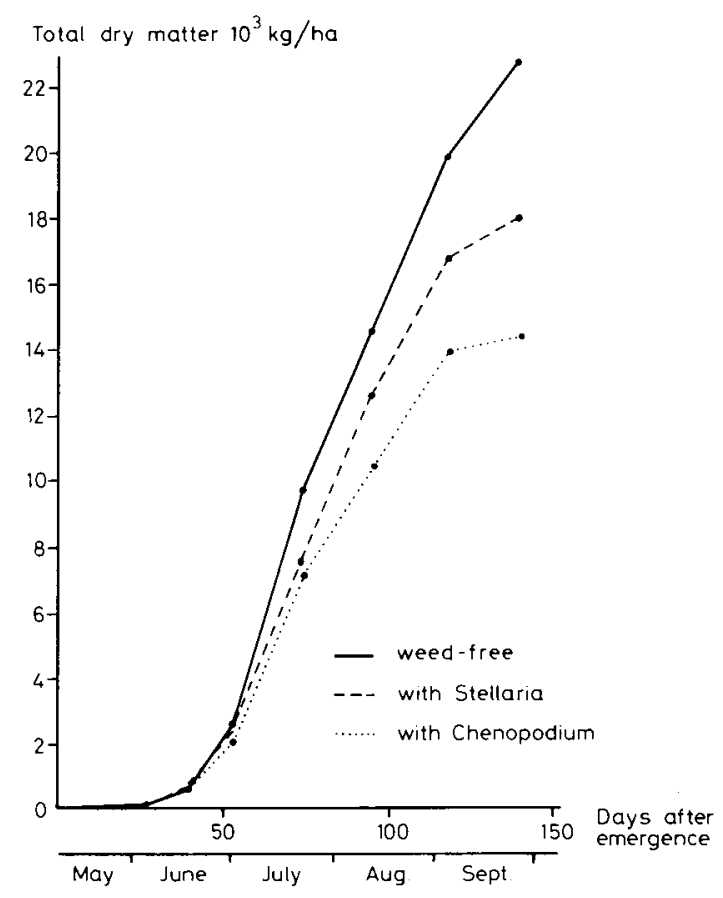

Fig. 1. Time courses of sugar beet biomass in monoculture and in mixture with fat hen and chickweed. 


\section{J. KROPFF ET AL.}

Table 1. Sugar beet production in monocultures and mixed cultures at final harvest in tha ${ }^{-1}$ and in $\%$ of weed-free crop (in parenthesis). Different letters indicate significant difference between treatments $(P$ $<0.05$, capitals $P<0.01$ ).

\begin{tabular}{lccc}
\hline & \multicolumn{2}{l}{ Sugar beet } & \\
\cline { 2 - 4 } & weed-free & with Stallaria & with Chenopodium \\
& & & \\
Total dry weight $\left(\mathrm{t} \mathrm{ha}^{-1}\right)$ & $23.1(100) \mathrm{a}(\mathrm{A})$ & $18.2(79) \mathrm{b}(\mathrm{AB})$ & $14.6(63) \mathrm{b}(\mathrm{B})$ \\
Shoot dry weight $\left(\mathrm{t} \mathrm{ha}^{-1}\right)$ & $8.6(100) \mathrm{a}(\mathrm{A})$ & $6.8(79) \mathrm{b}(\mathrm{AB})$ & $6.4(74) \mathrm{b}(\mathrm{B})$ \\
Root dry weight $\left(\mathrm{t} \mathrm{ha}^{-1}\right)$ & $14.5(100) \mathrm{a}$ & $11.3(78) \mathrm{ab}$ & $8.2(57) \mathrm{b}$ \\
& & & \\
Total fresh weight $\left(\mathrm{t} \mathrm{ha}^{-1}\right)$ & $61.9(100) \mathrm{A}$ & $48.9(79) \mathrm{B}$ & $33.1(53) \mathrm{C}$ \\
Sugar content $(\%)$ & $15.04 \mathrm{a}$ & $15.43 \mathrm{~b}$ & $15.43 \mathrm{~b}$ \\
Sugar production $\left(\mathrm{t} \mathrm{ha}^{-1}\right)$ & $9.3(100) \mathrm{A}$ & $7.5(81) \mathrm{B}$ & $5.1(55) \mathrm{C}$ \\
\hline
\end{tabular}
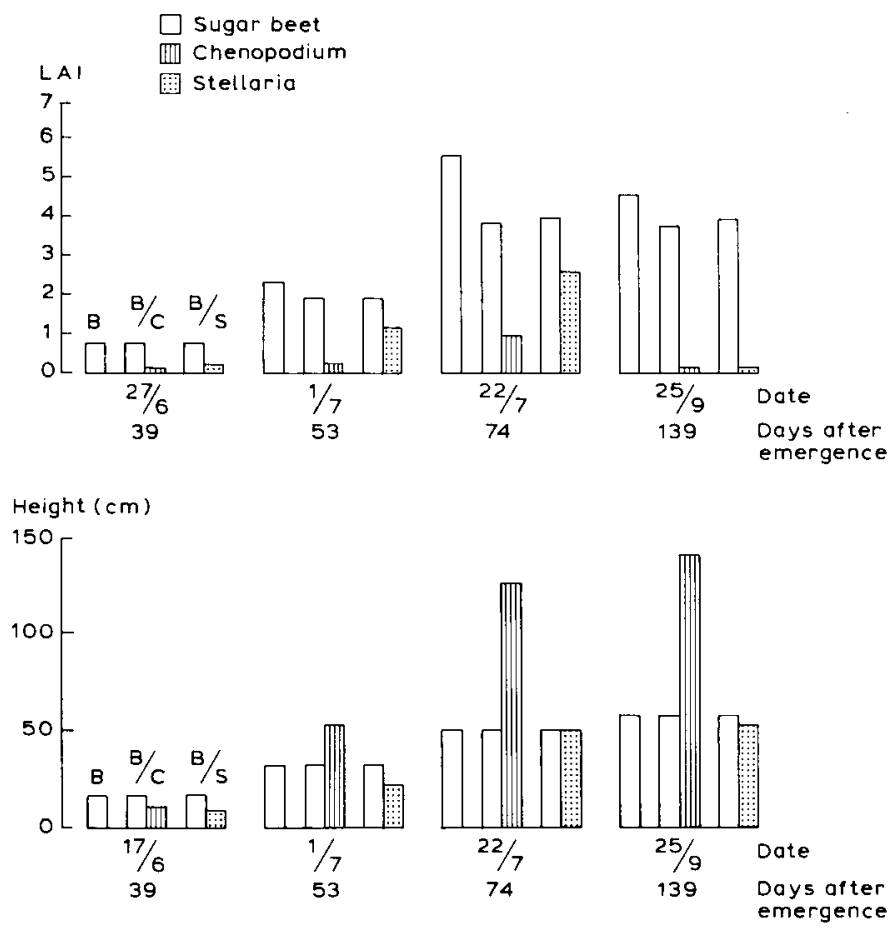

Fig. 2. Top: leaf area index of sugar beets in monoculture and mixtures and development of leaf area of fat hen and chickweed in mixture at various dates.

Bottom: plant height of sugar beets in monoculture (B) and mixture and fat hen (C) and chickweed $(\mathrm{S})$ in mixtures. 


\section{J. KROPFF ET AL.}

Chickweed had a much higher LAI than fat hen (Fig. 2). However, fat hen plants had a stronger effect than chickweed on sugar beet growth, probably because the fat hen plants were taller and able to shade the sugar beets (Fig. 2). This effect illustrates the importance of the factor plant height in crop weed competition.

In the 1985 experiment fat hen plants reduced crop production by $37 \%$, whereas in a similar field experiment carried out in 1984 fat hen plants reduced crop production by $78 \%$. Analysis of these two experiments with a simulation model of crop weed competition showed that the difference between years was mainly attributable to differences in relative times of emergence of the crop and the weeds: in 1984 the weeds emerged simultaneously with the crop, whereas in 1985 the fat hen plants emerged 12 days after the crop (Kropff, 1987). These results suggest that quantification of damage relationships should not be based upon weed density alone but on a combination of weed density and relative time of emergence.

\section{References}

Kropff, M. J., F. J. H. Vossen, C. J. T. Spitters \& W. de Groot, 1984. Competition between a maize crop and a natural population of Echinochloa crus-galli (C.). Netherlands Journal of Agricultural Science 32: 324-327.

Kropff, M. J.. 1987. Simulation of crop weed competition. In: Proceedings of the CEC meeting on weed control in vegetable crops (in press).

Spitters, C. J. T., 1984. A simple simulation model for crop weed competition. In: 7th Symposium on weed biology, ecology and taxonomy. (COLUMA-EWRS, Paris), p. 355-366..

This synopsis is based on an undergraduate thesis 'Konkurrentie tussen het gewas suikerbiet en de onkruiden melganzevoet en muur; veldexperiment en simulatie van monocultures' by L. Bastiaans, B. Habekotté, H. van Oene and R. Werner, Department of Theoretical Production Ecology, Wageningen Agricultural University, 1986. 126 pp., 44 figs., 27 tables, 105 refs., appendices.

Available as paper copy (order R075P, $f 30$ including postage) or microfiches (order R075M, f 17.50 including postage) at: NARD, c/o Pudoc, P.O. Box 4, 6700 AA Wageningen, Netherlands (telex 45015 blhwg). 